\title{
Effectiveness and maintenance of behavior change and exercise programs on depressive symptoms in older adults
}

\section{Efetividade e manutenção de programas de mudança de comportamento e de exercícios físicos sobre os sintomas depressivos de idosos}

\author{
Lucélia Justino Borges', Simone Teresinha Meurer², Tânia R. Bertoldo Benedetti²
}

\begin{abstract}
The aim of the study was to compare the effectiveness and maintenance of two health promotion programs on depressive symptoms (DS) of older adults. The research was conducted with the network of primary health care in a southern capital of Brazil. In total, 119 older adult participants were allocated into different groups: behavior change (BCG; $n=40$ ), exercise (EG; $n=51$ ) and control (CG; $n=28)$, assessed at baseline (A1) and followed-up at three (A2), six (A3) and twelve months (A4). BCG attended "VAMOS - Vida Ativa Melhorando a Saúde" (in English, Active Living Improving Health) program while EG attended aerobic gymnastic sessions. The DS were measured by the Geriatric Depression Scale (GDS-15) and level of physical activity (LPA) through accelerometers. Results show that only BCG reduced the number of older adults with high DS ( $\mathrm{A} 1=9 ; \mathrm{A} 2=4)$ and this reduction was maintained after six $(\mathrm{A} 3=3)$ and twelve months $(\mathrm{A} 4=4)$. Six older adults became physically active $(\mathrm{BCG}=3 ; \mathrm{EG}=2 ; \mathrm{CG}=1)$ after the intervention. However, there was no LPA maintenance after six and twelve months, once the frequency of insufficiently active older adults increased or was similar to baseline. When comparing DS, an interaction was found between group and assessment $(\mathrm{F}=2.94, \mathrm{p}=0.01)$ for $\mathrm{BCG}$, highlighting the reduction $(\mathrm{A} 1=4.0 ; \mathrm{A} 2=2.5)$ and maintenance $(\mathrm{A} 3=2.6 ; \mathrm{A} 4=2.8)$ of mean DS in this group. The results indicate that behavior change programs may bring benefits to the mental health of older adults and the VAMOS program seems to be a viable option for older adults in the community.
\end{abstract}

\section{Keywords}

Depression; Older Age; Behavior; Lifestyle; Motor Activity.

\section{Resumo}

Objetivou-se comparar a efetividade e a manutenção de dois programas de promoção da saúde sobre os sintomas depressivos (SD) da população idosa. A pesquisa foi desenvolvida no âmbito da rede de atenção primária à saúde de uma capital do sul do Brasil. Participaram 119 idosos alocados nos grupos: mudança de comportamento - GMC $(n=40)$, exercício físico - GEF $(n=51)$ e controle - GC $(n=28)$, avaliados no baseline (A1), após três (A2), seis (A3) e 12 meses (A4). O GMC participou do "VAMOS - Vida Ativa Melhorando a Saúde" e o GEF de aulas de ginástica. Os SD foram avaliados pela Geriatric Depression Scale (GDS-15) e o nível de atividade física (NAF) por acelerômetro. Os resultados indicam que após a intervenção, somente no GMC houve redução do número de idosos com $S D$ elevados $(A 1=9 ; A 2=4)$ e essa redução se manteve após seis $(A 3=3)$ e doze meses $(A 4=4)$. Em relação ao $N A F$, após a intervenção, seis idosos tornaram-se fisicamente ativos (GMC=3; $G E F=2$ e $G C=1$ ). Todavia, não foi observada manutenção do NAF após seis e doze meses, uma vez que a frequência de idosos insuficientemente ativos aumentou ou foi semelhante ao baseline. $\mathrm{Na}$ comparação dos $S D$, identificou-se interação grupo versus avaliação $(F=2,94, p=0,01)$ para $o G M C$, destacando redução $(A 1=4,0$; $A 2=2,5)$ e manutenção $(A 3=2,6 ; A 4=2,8)$ das médias dos $S D$ nesse grupo. Os resultados sinalizam que programas de mudança de comportamento podem oportunizar benefícios à saúde mental dos idosos e que o programa VAMOS mostrou-se uma possibilidade viável de desenvolvimento no contexto comunitário para esta população.

\section{Palavras-chave}

Depressão; Idoso; Comportamento; Estilo de vida; Atividade motora.

\section{Introduction}

There has been clear evidence of the inverse association between depressive symptoms and physical acti-

1 Federal University of Parana. Department of Physical Education, Curitiba, PR. 2 Federal University of Santa Catarina. Post-graduate program in Physical Education, Florianópolis, SC. vity levels ${ }^{1-8}$. In spite of the benefits of physical activity over the mental health of older adults ${ }^{9-13}, 38.2 \%$ of the Brazilian population of 65 years or older is physically inactive ${ }^{14}$ and is unaware of the benefits of this practice for mental health ${ }^{15}$. It is important to consider that the adoption of physical activity is complex and influenced 
by many aspects, such as intra and interpersonal, environmental and communitary ${ }^{16}$.

Therefore, there is a need to develop and test new strategies to help older adults to adopt behaviors that are more active. The use of pedometers, for example, may help establish goals and monitoring ${ }^{17,18}$ and, in older adults from Florianopolis, showed to be a positive ${ }^{19}$. Bird and Hawley ${ }^{20}$ highlighted the need for innovation that can be incorporated in daily life, resulting in benefits for health. In this context, programs for behavior change and promotion of healthy habits can be an important strategy for the increase of physical activity levels in older adults ${ }^{21,22}$, contributing for promotion and prevention of mental health ${ }^{17,21}$ and improvement in quality of life $\mathrm{e}^{23}$. Specifically, on the effectiveness of such program in the reduction of depressive symptoms, international studies have shown positive results after twelve ${ }^{23}$ and twenty weeks ${ }^{17}$ interventions.

Nonetheless, in Brazilian older adults, there is few evidence on the effectiveness and maintenance of the benefits from interventions with educational programs, such as behavior change, and these deserve to be researched. One of the aims of programs of this nature is offering knowledge and strategies to help participants make healthier choices related to a more active lifestyle, able to be added to daily activities and per their reality ${ }^{17,21,22}$. Therefore, it is expected that behavior change programs are more effective and may bring more sustainable benefits to health, when compared to a conventional physical exercise program.

The aim of this investigation was to compare effectiveness and maintenance of two programs (behavior change and physical exercise) on depressive symptoms in older adults, users of the primary health care system in capital in Southern Brazil.

\section{Methods}

This study is part of the Project "VIA - Vida ativa: descobrindo caminhos saudáveis" (in English, Active living: finding healthy ways), currently known as "VAMOS - Vida Ativa Melhorando a Saúde" (in English, Active Living Improving Health), a collaborative study between Brazil (Center for Sports/Federal University of Santa Catarina) and the United States (University of Illinois at Urbana-Champaign).

VAMOS is a behavior change program, founded on the socio-cognitive theory, based on the Active Living Every Day (ALED), as proposed by Human Kinetics. The detailed methods of the program and the intervention study, a community essay, has been previously described ${ }^{24}$. The study was conducted in six Health Centers (HC) in Florianopolis/Santa Catarina, located in two Health Regionals (North and East). The HC in each Health Regional were randomized in behavior change group (BCG; $n=2)$; exercise group (EG; $n=2$ ) and control group (CG; $n=2)$. The target population in the study were older adults, users of the HC in the previous six months. For sample composition, the following criteria were used: being 60 years or older; being interested in participating in the study; not having severe physical disabilities and/or cognitive impairment (based on the results of the Mini-Mental State Examination).

For this study, all the older adults who participated in the first assessment (baseline) of the depressive symptoms composed the sample. That is, 119 older adults (95 women), with ages from 60 to 95 years $(70.5 \pm 7,1)$, in the three different groups: BCG $(n=40), E G(n=51)$ and CG $(n=28)$.

The BCG participated in the VAMOS program focused on physical activity promotion, during three months, on weekly meetings of approximately two hours, with content related to physical activity and adoption of a healthy lifestyle. The meetings aimed at increasing self-efficacy and motivation for physical activity of older adults, help in time management to include physical activity in daily life, identify barriers and 
facilitators for an active lifestyle as well as social support to overcome barriers for physical activity and, thus, help the promotion of daily behavior change of the older adults.

The EG was submitted to three weekly sessions of physical exercise (aerobic gymnastic) of 60 minutes/session for three months, aimed at developing components of physical fitness related to health. The sessions were divided in three parts: initial (warm-up); main (development of physical capacities) and final (stretching). The exercises were done individually, in pairs and in small groups (circuit) or involving all of the participants, depending on the activity to be developed. The cardiac frequency was monitored at the end of warm-up manually, by counting pulses in the radial artery. Materials used were batons, bells, ankle weights, balls, mats and hoops, and exercises without any materials. The metric count with or without verbal cues was a strategy adopted during the execution of exercises.

Both interventions (EG and BCG) were conducted by Physical Education professionals linked to the Primary Health network in the municipality of Florianopolis, previously trained. The CG was not submitted to intervention.

Data collection was conducted in four assessments: baseline [A1], after three [A2], six [A3] and 12 months [A4]. The number of older adults participating in each assessment is presented in the diagram (Figure 1). There was one death during the study and were considered as dropouts those who stopped attending the interventions and never returned.

The data collection team was composed by Physical Education professionals and students, previously trained.

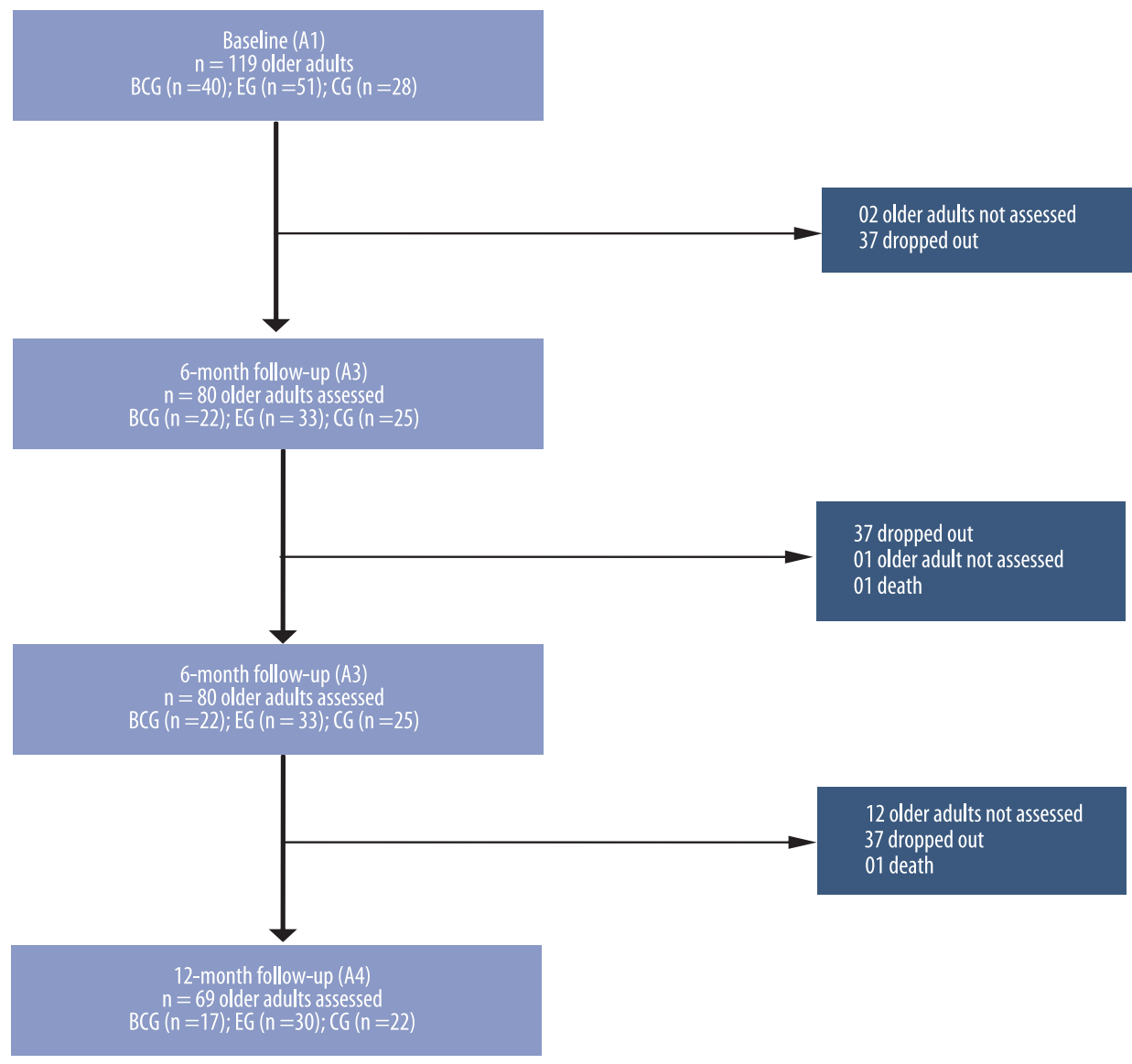

FIGURE 1 - Flow chart of sample, according to the assessment of depressive symptoms in older adults participating in the VAMOS program, Florianopolis, 2012/2013. 
The assessment of depressive symptoms was conducted through the Geriatric Depression Scale (GDS-15), using 5/6 (non-case/case) as cut-points ${ }^{25}$. The level of physical activity was assessed by accelerometer ActiGraph GT3X and GT3X ${ }^{+}$, used on the waist, during seven days, with data collected to 60-second epochs. Data were analyzed with the software ActiLife version $6.7 .2^{\circledast}$, being considered valid the data from the older adults who accumulated at least 10 hours of daily recording during at least four days, being three weekdays and one weekend day. The total time in moderate to vigorous physical activity (MVPA) was used, and sedentary behavior was calculated by the time spent in activities of low energy expenditure [1 to $1.5 \mathrm{MET}$ ]. The cut-point of $150 \mathrm{~min} /$ week of MVPA was used to classify the level of physical activity of older adults. ${ }^{26}$

Considering this is a follow-up study and that loss of information throughout the assessments is a common problem in Health research ${ }^{27}$, there was an option for the intention of treating the data. Confirming such problem and the reality of intervention research, we highlight only 58 older adults completed all assessments (BCG $(n=12), E G(n=25)$ and CG $(n=21)$. An input for the last observation of the outcome variable (depressive symptoms) and for level of physical activity, assuming there were no changes to those variables among those who, at some point, left the study. There was no input of data for the participant who passed away during the study.

The data analysis was descriptive (mean, standard deviation, frequency and relative frequency). Chi-square test was used to compare sociodemographic characteristics and analysis of variance (ANOVA) one way to compare means of age. For the comparison of scores of depressive symptoms intra and intergroup considering physical activity as covariable in the different assessments, after confirmation of normality of residual, the ANOVA two way for repeated measures, with a post hoc Bonferroni's test. Since the hypothesis for spheroid was broken, the Greenhouse-Geisser correction was used. Analyses were conducted using software SPSS version 21.0 with a significance level of $5 \%$.

The study complied with ethical precepts and was approved in the National Committee of Research Ethics (\# 480.560) and the Ethics Committee in Human Research, of the Federal University of Santa Catarina, under the review \# 2387.

\section{Results}

Most of the older adults presented low education; were married; retired and with low monthly family income. On the comparison of proportions, the groups were similar for sociodemographic variables. However, on physical activity, the groups were different among themselves. The higher frequencies of active older adults were in BCG and EG, respectively.

It is also important to highlight that $90.8 \%$ of participants took medications (3.8 \pm 2.3$)$; most of them considered their health as regular (40.3\%) and good (38.7\%); and, in the perception of most older adults (71.4\%), their health status did not obstruct their performance of physical activity.

Table 2 shows results on depressive symptoms in the different assessments. After the intervention, only BCG showed reduction in older adults with high depressive symptoms and this maintained after six and twelve months.

Related to the physical activity level, after the intervention, three participants from BCG and two from EG became physically active. However, in all groups, after six and twelve months, the frequency of insufficiently active older adults was higher or similar to the baseline. For sedentary behavior, there was reduction in the mean from BCG after intervention and this was maintained in the follow-up. 
However, the EG also presented reduction in the time spent in sedentary activities on A3 and A4 (Table 3).

TABLE 1 - Sociodemographic characteristics of older adults and level of physical activity according to the distribution of the intervention groups, Florianopolis, 2012.

\begin{tabular}{|c|c|c|c|c|c|}
\hline \multirow{3}{*}{ Variables } & \multicolumn{5}{|c|}{ Groups } \\
\hline & Total & $B C G$ & EG & CG & \\
\hline & $n(\%)$ & $n(\%)$ & $n(\%)$ & $n(\%)$ & $p$ \\
\hline \multicolumn{6}{|l|}{ Sex } \\
\hline Male & $24(20.2)$ & $10(25.0)$ & 09 (17.6) & 05 (17.9) & 0.65 \\
\hline Female & $95(79.8)$ & $30(75.0)$ & $42(82.4)$ & $23(82.1)$ & \\
\hline \multicolumn{6}{|l|}{ Age (years)* } \\
\hline $60-69$ & $59(49.6)$ & $20(51.3)$ & $22(43.1)$ & $17(60.7)$ & 0.34 \\
\hline $60-79$ & $42(35.6)$ & $13(33.3)$ & $19(37.3)$ & $10(35.7)$ & \\
\hline 80 or more & $17(14.4)$ & $06(15.4)$ & $10(19.6)$ & 01 (3.6) & \\
\hline \multicolumn{6}{|l|}{ Education (years of formal study)* } \\
\hline Illiterate (0) & $08(6.7)$ & $03(2.5)$ & $04(7.8)$ & $01(6.1)$ & 0.48 \\
\hline Incomplete grade school (1-7) & $64(53.8)$ & $20(50.0)$ & $28(54.9)$ & $16(57.1)$ & \\
\hline Complete grade school (8) & $14(11.8)$ & $02(5.0)$ & $07(13.7)$ & 05 (17.9) & \\
\hline Incomplete high school (9-10) & $04(3.4)$ & $01(2.5)$ & $02(3.9)$ & $01(3.6)$ & \\
\hline Complete high school (11) & $14(11.8)$ & 05 (12.5) & 05 (9.8) & $04(14.3)$ & \\
\hline Complete college/undergraduate & $09(7.6)$ & $06(15.0)$ & $03(5.9)$ & - & \\
\hline Graduate school & $04(3.4)$ & $02(5.0)$ & $02(3.9)$ & - & \\
\hline Marital status* & & & & & 0.20 \\
\hline Single & $05(4.2)$ & - & $04(7.8)$ & $01(3.6)$ & \\
\hline Married/stable relationship & $63(5.2)$ & $24(60.0)$ & $27(52.9)$ & $12(42.9)$ & \\
\hline Widowed & $32(27.1)$ & $08(20.0)$ & $16(31.4)$ & $08(28.6)$ & \\
\hline Separated/Divorced & $17(14.4)$ & $07(17.5)$ & $04(7.8)$ & $06(21.4)$ & \\
\hline Occupation & & & & & 0.53 \\
\hline Retired & $72(60.5)$ & $25(62.5)$ & $29(56.9)$ & $18(64.3)$ & \\
\hline Pensioner & $19(16.0)$ & $05(12.5)$ & $09(17.6)$ & $05(17.9)$ & \\
\hline Retired and pensioner & 09 (7.6) & $03(7.5)$ & 05 (9.8) & $01(3.6)$ & \\
\hline Active retiree & $02(1.7)$ & $01(2.5)$ & $01(2.0)$ & - & \\
\hline Active stipends & $03(2.5)$ & $01(2.5)$ & - & $02(7.1)$ & \\
\hline Active without stipends & $12(9.2)$ & $03(7.5)$ & $07(13.7)$ & $02(7.1)$ & \\
\hline \multicolumn{6}{|l|}{ Monthly family income (minimum wage) ${ }^{*}$} \\
\hline$<1$ & $08(6.7)$ & $01(2.5)$ & $05(9.8)$ & $02(7.1)$ & 0.26 \\
\hline $1-12$ & $26(21.8)$ & $09(22.5)$ & $09(17.6)$ & $08(28.6)$ & \\
\hline $2-13$ & $22(18.5)$ & $07(17.5)$ & 09 (17.6) & $06(21.4)$ & \\
\hline $3-14$ & $29(24.4)$ & $11(27.5)$ & $14(27.5)$ & $04(14.3)$ & \\
\hline $4-16$ & $13(10.9)$ & $03(7.5)$ & $07(13.7)$ & $03(10.7)$ & \\
\hline$>6$ & $13(10.9)$ & $08(20.0)$ & $04(7.8)$ & $01(3.6)$ & \\
\hline Doesn't know & $03(4.2)$ & - & $02(3.9)$ & $01(3.6)$ & \\
\hline \multicolumn{6}{|l|}{ Level of Physical Activity* } \\
\hline Physically active & $38(31.9)$ & $17(48.6)$ & $10(20.8)$ & $11(42.3)$ & 0.02 \\
\hline Insufficiently active & $81(68.1)$ & $18(51.4)$ & $38(79.2)$ & $15(57.7)$ & \\
\hline
\end{tabular}

*There are undeclared cases; $\mathrm{BCG}=$ behavior change group; $\mathrm{EG}=$ exercise group; $\mathrm{CG}=$ control group. 
TABLE 2 - Distribution of depressive symptoms, according to different assessments, Florianopolis. 2012/2013.

\begin{tabular}{|c|c|c|c|c|}
\hline \multirow{3}{*}{$\begin{array}{l}\text { Groups/ } \\
\text { Depressive } \\
\text { symptoms }\end{array}$} & \multicolumn{3}{|c|}{ Assessment } & \multirow[b]{2}{*}{ A4 } \\
\hline & A1 & $A 2$ & A3 & \\
\hline & $n(\%)$ & $n(\%)$ & $n(\%)$ & $n(\%)$ \\
\hline \multicolumn{5}{|l|}{ Behavior change } \\
\hline Normal & $31(77.5)$ & $36(90.0)$ & $37(92.5)$ & $36(90.0)$ \\
\hline Suspicion of depression & $09(22.5)$ & $04(10.0)$ & $03(7.5)$ & $04(10.0)$ \\
\hline \multicolumn{5}{|l|}{ Physical exercise } \\
\hline Normal & $43(84.3)$ & $42(82.4)$ & $42(82.4)$ & $44(86.3)$ \\
\hline Suspicion of depression & $08(15.7)$ & 09 (17.6) & $09(17.6)$ & $07(13.7)$ \\
\hline \multicolumn{5}{|l|}{ Control } \\
\hline Normal & $23(82.1)$ & $23(82.1)$ & $25(89.3)$ & $24(85.7)$ \\
\hline Suspicion of depression & 05 (17.9) & 05 (17.9) & $03(10.7)$ & $04(14.3)$ \\
\hline
\end{tabular}

$A 1=$ baseline; $A 2$ = 3-month follow-up; $A 3=6$-month follow-up; $A 4=12$-month follow-up.

TABLE 3 - Level of physical activity in older adults, according to different assessments, Florianopolis. 2012/2013.

\begin{tabular}{|c|c|c|c|c|}
\hline \multirow{3}{*}{$\begin{array}{l}\text { Groups/ } \\
\text { Level of } \\
\text { physical activity }\end{array}$} & \multicolumn{4}{|l|}{ Assessment } \\
\hline & $\mathrm{A} 1$ & $A 2$ & A3 & A4 \\
\hline & $n(\%)$ & $n(\%)$ & $n(\%)$ & $n(\%)$ \\
\hline \multicolumn{5}{|l|}{ Behavior change* } \\
\hline Physically active & $17(48.6)$ & $20(57.1)$ & $16(45.7)$ & $16(45.7)$ \\
\hline Insufficiently active & $18(51.4)$ & $15(42.9)$ & $19(54.3)$ & $19(54.3)$ \\
\hline Sedentary behavior ${ }^{\dagger}$ & $3171.8(874.0)$ & 3037.5 (789.2) & $3054.9(737.6)$ & $3063.4(775.3)$ \\
\hline Time in MVPA/week (min/wk.) & $188.5(166.5)$ & $218.1(175.0)$ & $190.5(177.2)$ & $181.1(159.6)$ \\
\hline \multicolumn{5}{|l|}{ Physical Exercise* } \\
\hline Physically active & $10(20.8)$ & $12(25.0)$ & $09(18.4)$ & $10(20.4)$ \\
\hline Insufficiently active & $38(79.2)$ & $36(75.0)$ & $40(81.6)$ & $39(79.6)$ \\
\hline Sedentary behavior ${ }^{\dagger}$ & $3201.6(833.7)$ & $3385.4(1100.6)$ & $3508.0(1025.9)$ & $3485.2(901.6)$ \\
\hline Time in MVPA/week (min/wk.) & $98.2(112.3)$ & $114.8(119.2)$ & $85.4(92.1)$ & $82.6(86.3)$ \\
\hline \multicolumn{5}{|l|}{ Control* $^{*}$} \\
\hline Physically active & $11(42.3)$ & $10(50.0)$ & $10(38.5)$ & $09(36.0)$ \\
\hline Insufficiently active & $15(57.7)$ & $13(50.0)$ & $16(61.5)$ & $16(64.0)$ \\
\hline Sedentary behavior ${ }^{\dagger}$ & $3331.3(791.4)$ & $3367.3(664.7)$ & $3208.9(716.0)$ & $3171.1(909.7)$ \\
\hline Time in MVPA/week (min/wk.) & $156.9(149.3)$ & $168.4(140.5)$ & $133.6(113.3)$ & $125.2(105.9)$ \\
\hline
\end{tabular}

$\mathrm{A} 1=$ baseline; $\mathrm{A} 2=3$-month follow-up; $\mathrm{A} 3=6$-month follow-up; $\mathrm{A} 4=12$-month follow-up; ${ }^{*}$ There are non-declared cases; † Mean and standard deviation; MVPA=moderate to vigorous physical activity.

Statistical difference was found only for means of MVPA. The mean time spent in these activities by the BCG (A1=188.5; $\mathrm{A} 2=218.1$; $\mathrm{A} 3=190.5$; $\mathrm{A} 4=181.1)$ was statistically higher from the EG (A1=98.2; $\mathrm{A} 2=114.8 ; \mathrm{A} 3=85.4 ; \mathrm{A} 4=82.6)$ in the four assessments $(\mathrm{p}=0.013$; $\mathrm{p}=0.005 ; \mathrm{p}<0.001 ; \mathrm{p}<0.001)$ (Table 3$)$. When comparing depressive symptoms, for the data without input, there was no isolated effect for the group $(\mathrm{F}=0.38 ; \mathrm{p}=0.68)$ or the assessment $(\mathrm{F}=0.86, \mathrm{p}=0.45)$, nor the interaction between groups versus assessment $(\mathrm{F}=1.54 ; \mathrm{p}=0.17)$. However, the analysis with input data showed interaction between group versus assessment $(\mathrm{F}=2.94, \mathrm{p}=0.01)$, being the $B C G$ where the reduction $(A 1=4.0 ; A 2=2.5)$ and maintenance $(A 3=2.6$; $\mathrm{A} 4=2.8$ ) of means occurred for depressive symptoms (Table 4 ). 
TABLE 4 - Comparison of depressive symptoms in different assessments, considering level of physical activity of older adults, Florianopolis. 2012/2013.

\begin{tabular}{|c|c|c|c|c|c|c|}
\hline \multirow{4}{*}{ Assessment } & \multicolumn{6}{|c|}{ Depressive Symptoms* } \\
\hline & \multicolumn{2}{|c|}{ Behavior Change } & \multicolumn{2}{|c|}{ Physical Exercise } & \multicolumn{2}{|c|}{ Control } \\
\hline & \multicolumn{2}{|c|}{ Mean $(S D)^{* *}$} & \multicolumn{2}{|c|}{ Mean $(\mathrm{SD})^{* *}$} & \multicolumn{2}{|c|}{ Mean $(S D)^{* *}$} \\
\hline & No input & With input & No input & With input & No input & With input \\
\hline $\mathrm{A} 1$ & $4.0(2.7)$ & $4.0^{\dagger}(2.8)$ & $3.1(2.6)$ & $3.1(2.7)$ & $3.6(2.8)$ & $3.7(2.9)$ \\
\hline A2 & $3.0(2.5)$ & $2.5(2.5)$ & $3.0(2.8)$ & $2.9(2.8)$ & $3.7(2.5)$ & $3.6(2.3)$ \\
\hline A3 & $3.1(2.3)$ & $2.6(2.2)$ & $3.0(3.2)$ & $3.0(3.2)$ & $3.1(2.2)$ & 3.0 (2.1.) \\
\hline A4 & $3.4(2.4)$ & $2.8(2.3)$ & $2.8(2.6)$ & $2.8(2.7)$ & $3.3(2.5)$ & $3.0(2.5)$ \\
\hline
\end{tabular}

${ }^{*}$ covariable=level of physical activity; $A 1$ = baseline; $A 2=3$-month follow-up; $A 3=6$-month follow-up; A4=12-month follow-up. ${ }^{* *}$ standart deviation. ${ }^{+}$Statistically different from A2, A3 and A4 $(p<0.05)$.

\section{Discussion}

This investigation conducted in the community context of a capital in Southern Brazil, to the knowledge of the authors, is the first to assess the effectivity and maintenance of two programs for health promotion (behavior change and physical exercise) on depressive symptoms in older adults, users of the primary health care network.

There was evidence of the significant reduction of depressive symptoms after the intervention in the BCG and maintenance of this reduction in the follow-up assessments. The results identified are similar to other interventions that used behavior change programs for physical activity promotion. Wilcox et $\mathrm{al}^{17}$ reported the effectiveness of a behavior change program - ALED, based on socio-cognitive theory and the trans theoretical model. The intervention lasted for 20 weeks and, among the results, the reduction of depressive symptoms was observed, as well as the increase in the volume of moderate to vigorous physical activity in older adults living in the community.

Kerr et $\mathrm{al}^{23}$ conducted an intervention with a sample of 36 depressive patients and associated medication with a behavior change program based on socio-cognitive theory. After 12 weeks, there was reduction in the depressive symptoms, increase in scores of quality of life and increase in the volume of physical activity.

Another study conducted with 624 older adults ${ }^{21}$, also structured on socio-cognitive theory, did not find effects of the intervention on depressive symptoms in a general analysis. Nonetheless, when analyzing the results by different groups, those participating in the intervention with light depressive symptoms at baseline decreased those symptoms, while those in the same group and participants in the control group increased their depressive symptoms.

Once the reality of the Brazilian generation is aged, there is belief in the relationship between information/education/action looking to transform the information in knowledge and action for health ${ }^{19}$. Therefore, the VAMOS seems to be a program that can support the development of this relationship once its aim is to provide knowledge and strategies to help the adoption of an active lifestyle $e^{24}$. Programs such as this could be an alternative for promotion of physical activity, also reaching those who do not like conventional physical exercise programs, do not have the opportunity and/or cannot be inserted in such programs. Moreover, counseling actions looking to adopt healthy habits, including physical activity, become important strategies to be developed by primary health care ${ }^{28}$, in order to lower inequities in health.

The results did not evidence a significant reduction in depressive symptoms for participants in the EG. Even though there was the hypothesis of VAMOS being 
more effective than the exercise program, it was expected that there was a reduction of depressive symptoms in EG. There is evidence in the literature on the benefits of physical exercise in the reduction of depressive symptoms in those with a diagnosis ${ }^{13}$, as well as those without a diagnosis of depression ${ }^{29}$, and that physical activity interventions, supervised or not, improve depressive symptoms ${ }^{29}$. A few speculations for these results are: a) the activities could be insufficient to promote physiological alterations in mental health; b) the low level of physical activity of the EG at baseline could signal the lack of motivation for practice or functional limitation, minimizing the possible effects in mental health; c) the aims of the sessions for the EG focused on components of physical fitness.

The level of physical activity, used as a covariable in the comparison of depressive symptoms in the different assessments, may not have influenced the results, once the number of insufficiently active older adults did not lower after the interventions and six and twelve months after, the frequency of those increased or was similar to the baseline for all groups. On the other hand, a reduction of time spent in sedentary behavior was identified, as well as the maintenance of this reduction in BCG. That is, the participants in the BCG seem to have transformed sedentary habits in active behavior. This modification could have contributed to the positive results observed in this group.

Nevertheless, in the CG there was reduction in the mean of sedentary behavior, after six and twelve months. Therefore, even though no systematic physical activity was offered to the CG by the project, they could have participated in sporadic or systematic activity in the community. Furthermore, the fact that participants in the CG were assessed periodically on physical activity and have received personal results could have waken the interest and motivation for their daily behavior.

In this way, even though the VAMOS intervention did not result in direct increase on the volume of moderate to vigorous physical activity, we believe it can have reflected positively on mediators of physical activity such as self-efficacy and social support ${ }^{30}$. These aspects are evidenced in the theoretical support for the development of VAMOS, which were focused on throughout the intervention and may have contributed to the reduction of the depressive symptoms. These possible modifications on psychosocial mediators may explain the alterations in sedentary behavior, as well as VAMOS may have influenced other behaviors (nutrition, quality of sleep) which may influence mental health in older adults.

The limitations of the present study are based on the differences in the levels of physical activity between the groups at baseline; low frequency of older adults with high levels of depressive symptoms at baseline, which could have a peak effect in the results; lack of control for other variables such as the use of antidepressant, diagnosis of depression and mediators of behavior (physical activity) and physical activity in the CG. Even though there was control in the number of absences for BCG and EG, this information was not used due to the lack of data for some of the participants. Furthermore, the comparison between the groups may be limited due to the non-pairing of groups after follow-up losses; as well as the lack of information on those who dropped out during the intervention.

The present study identified the reduction and maintenance of depressive symptoms in older adults participating in the BCG, signaling that programs of this nature can also offer benefits to mental health. Although, the results are limited to the context of the sample and must be analyzed with caution, indicating more research needs to be done, specially in the sense to understand which etiological factors of behavior change contribute to the reduction of depressive symptoms. 
It is important to highlight that this study was conducted in the community context and both interventions were led by Physical Education professionals working in Primary Health Care system. Therefore, we believe new methodologies for health promotion, such as behavior change programs, may be inserted in the reality of public health, looking to broaden the knowledge and autonomy of users in respect to their health. We suggest new interventions should be conducted in the community context, potentiate the impact of research in public health and that future research should include assessment and analysis of psychosocial mediating variables of physical activity behavior.

\section{Acknoledgements}

This study was funded by the Lemann Institute (collaborative research between Brazil - Federal University of Santa Catarina - and the United States - University of Illinois at Urbana-Champaign). Additionally, the National Council for Technological and Scientific Development (CNPq, Universal 14/2012, process \#475.075/2012) and the Coordination for the Improvement of Higher Education Personnel (CAPES), through the concession of scholarship for sandwich doctorate abroad (Process BEX-7728/13-1) and scholarship for doctoral studies.

\section{Authors' contributions}

L.J. Borges and S.T. Meurer conducted fieldwork, analysis and interpretation of data, literature review and discussion of results, writing and review of the manuscript. T.R.B. Benedetti was responsible for the conception and coordination of the VAMOS Project, writing and critical review of the manuscript. All authors approved the final version.

\section{Conflict of interest}

The authors declare no conflicts of interest.

\section{References}

1. Benedetti TRB, Borges LJ,Petroski EL, Gonçalves LHT. Physical activity and mental health status among elderly people. Rev. Saúde Pública 2008;42(20):302-07.

2. Ku PW; Fox KR, Chen LJ. Physical activity and depressive symptoms in Taiwanese older adults: a seven-year follow-up study. Prev Med 2009;48(3):250-55.

3. Smith TL, Masaki KH, Fong K et al. Effect of Walking Distance on 8-Year Incident Depressive Symptoms in Elderly Men with and without Chronic Disease: The HonoluluAsia Aging Study. J Am Geriatr Soc 2010;58(8):1447-52.

4. Reichert CL, Diogo CL, Vieira JL, Dalacorte RR. Physical activity and depressive symptoms in community-dwelling elders from southern Brazil. Rev. Bras. Psiquiatr. 2011;33(2):165-70.

5. Giuli C, Papa R, Mocchegiani E, Marcellini F. Predictors of participation in physical activity for community-dwelling elderly Italians. Arch Gerontol Geriatr 2012;54(1):50-4.

6. Korniloff K, Häkkinen A, Koponen H. et al. Relationships between depressive symptoms and self-reported unintentional injuries: the cross-sectional population-based FIN-D2D survey. BMC Public Health 2012, 12(516):1-7.

7. Borges LJ, Benedetti TRB, Xavier AJ, d'Orsi E. Factors associated with depressive symptoms in older adults: Epi Floripa study. Rev. Saúde Pública 2013; 47(4):701-10.

8. Minghelli B, Tom B, Nunes C, Neves A, Simões C. Comparison of anxiety and depression levels among active and sedentary older adults. Rev Psiq Clín. 2013;40(2):71-6.

9. Moraes H, Deslandes A, Ferreira C, Pompeu F, Ribeiro P, Laks J. Physical exercise for treatment of depression in older adults: sistematic review. Rev. Psiquiatr. Rio Gd. Sul 2007,29(1):70-9.

10. Krogh J, Nordentoft M, Sterne JA, Lawlor DA. The effect of exercise in clinically depressed adults: systematic review and meta-analysis of randomized controlled trials. J Clin Psychiatry 2011;72(4):529-38. 
11. Robertson R, Robertson A, Jepson R, Maxwell M. Walking for depression or depressive symptoms: a systematic review and meta-analysis. Ment Health Phys Act 2012; 5(1):66-75.

12. Deslandes A. The biological clock keeps ticking, but exercise may turn it back. Arq Neuropsiquiatr 2013;71(2):113-18.

13. Silveira $\mathrm{H}$, Moraes $\mathrm{H}$, Oliveira $\mathrm{N}$ et al. Physical exercise and clinically depressed patients: a systematic review and meta-analysis. Neuropsychobiology 2013;67(2):61-68.

14. Brasil. Ministério da Saúde. Secretaria de Vigilância em Saúde. Secretariat for Strategic and Participative Management. Vigitel Brasil 2014: vigilância de fatores de risco e proteção para doenças crônicas por inquérito telefônico. Brasília: Ministério da Saúde, 2015.

15. Deslandes AC. Physical exercise in the prevention and treatment of most prevalent mental illnessess in older adults (Depression, Alzheimer's and Parkinson's). In: Júnior EDD A. (Ed.). Envelhecimento e Vida Saudável. Rio de Janeiro, 2009, cap.8, p.141-159.

16. Coleman MT, Pasternak RH. Effective strategies for behavior change. Prim Care 2012; 39(2):281-305.

17. Wilcox S, Dowda M, Griffin SF et al. Results of the first year of active for life: translation of 2 evidence-based physical activity programs for older adults into community settings. Am J Public Health 2006;96(7):1201-09.

18. Piette JD, Richardson C, Himle J et al. A randomized trial of telephone counseling plus walking for depressed diabetes patients. Med Care. 2011; 49(7):641-648.

19. Borges LJ, Guidarini FCS, Gerage AM et al. Pedometers: strategy for physical actvity promotion in older adults. Rev Bras Geriatr Gerontol 2014; 17(1):211-13.

20. Bird SR, Hawley JA. Exercise and type 2 diabetes: new prescription for an old problem. Maturitas 2012; 72(4):311-16.

21. Pakkala I, Read S, Leinonen R, Hirvensalo $M$ et al. The effects of physical activity counseling on mood among 75-to 81-year-old people: a randomized controlled trial. Prev Medicine 2008;46 (5):412-18.

22. Wilcox, s.; dowda, m.; leviton, 1. C.Active for life: final results from the translation of two physical activity programs. Am J Prev Medicine 2008;35(4):340-51.

23. Kerr J, Calfas KJ, Caparosa S. A pilot study to assess the feasibility and acceptability of a community based physical activity intervention (involving internet, telephone, and pedometer support), integrated with medication and mood management for depressed patients. Mental Health and Physical Activity 2008;1(1):40-45.

24. Benedetti TRB, SchwingelA, Gomez LSR, Chodzko-Zajko W. "VAMOS" program (Vida Ativa Melhorando a Saúde): from conception to results. Rev Bras Cineantropom Desempenho Hum 2012,14(6):723-37.

25. Almeida OP, Almeida SA. Reliability of the Brazilian version of the geriatric depression scale (GDS) brief version. Arq Neuropsiquiatria 1999;57(2B): 421-6.

26. WHO. World Health Organization. Global recommendations on physical activity for health. 2010.

27. Nunes L; Klück M, Fachel J. Comparison in single and multiple input methods using a risk model for surgical mortality. Rev. bras. epidemiol 2010;13(4): 596-606.

28. Siqueira FV, Nahas MV, Facchini LA et al. Factors considered as most important for maitenance of health. Rev Saúde Pública 2009;43(6):961-71.

29. Conn VS. Depressive symptom outcomes of physical activity interventions: meta-analysis findings. Ann Behav Med. 2010; 39(2):128-138.

30. Becofsky K, Baruth M, Wilcox S. Psychosocial Mediators of Two Community-Based Physical Activity Programs. Ann Behav Med. 2014; 48(1):1-5.

Corresponding

Author

Lucélia Justino Borges

luceliajb@yahoo.com.br
Federal University of Parana - UFPR

Department of Physical Education

Rua Coração de Maria, 92 | Jardim

Botânico. Curitiba - PR. CEP 80.210-132

Phone: +55 (41) 3360-4325
RECEIVED

REVISED

$27 / 05 / 2016$

$27 / 12 / 2016$

$04 / 01 / 2017$ 